\title{
Identifikasi Struktur Sesar Bawah Permukaan dengan Menggunakan Konfigurasi Half-Schlumberger (Head-On) pada Eksplorasi Panasbumi Daerah Mataloko
}

\author{
Eko Minarto* \\ Laboratorium Geofisika Jurusan Fisika, FMIPA, Institut Teknologi Sepuluh Nopember, Kampus ITS Sukolilo, Surabaya 60111 \\ Tarto Astoro \\ Jurusan Geofisika dan Meteorologi, Institut Teknologi Bandung \\ Jl. Ganesa 10, Bandung 40132

\section{Intisari} \\ Penyelidikan panasbumi daerah Mataloko dengan metode Head-on (Half-Schlumberger) yang didukung oleh \\ data geologi, menunjukkan bahwa daerah tersebut mempunyai struktur pengontrol yang memenuhi persyaratan \\ sebagai daerah yang berpotensi panasbumi. Hasil penyelidikan menunjukkan adanya struktur sesar normal, \\ dengan kemiringan 53o mengarah Barat Laut-Tenggara, serta adanya beberapa sesar yang telah tertimbun oleh \\ produk-produk muda. Dari data geologi, struktur sesar diatas adalah sesar Waeluja yang dicirikan oleh adanya \\ deretan mata air panas, kelurusan sungai Waeluja dan penyebaran batuan ubahan disekitar sesar
}

KATA KUNCI: Head-on, Half-Schlumberger, panasbumi

\section{PENDAHULUAN}

Indonesia merupakan daerah yang berpotensi akan sumber daya alam, termasuk sumber daya panasbumi (geothermal). Diperkirakan Indonesia mempunyai cadangan potensi sekitar 20.000 MW sumber panasbumi, dan sampai saat ini baru sekitar $10 \%$ dari cadangan yang ada atau 2000 MW yang sudah dieksplorasi. Sehingga perlu dilakukan penyelidikan lebih lanjut untuk pemanfaatan sumber daya panasbumi yang cukup potensial tersebut. Salah satu metode geofisika yang digunakan dalam mengidentifikasi struktur bawah permukaan dalam penyelidikan panasbumi adalah metode tahanan jenis dengan konfigurasi Head-on (Half-Schlumberger). Kondisi ideal geologi yang memenuhi persyaratan daerah panasbumi yang dapat menghasilkan uap panas adalah adanya sumber panas (heat source), adanya batuan reservoir dengan porositas dan permeabilitas cukup tinggi berisi fluida panas (ada pengisian kembali air dingin melalui rekahan atau sesar), serta adanya batuan penutup (cap rock) yang dapat menahan pelepasan panas [4].

\section{TINJAUAN DAERAH PENYELIDIKAN}

Sumber panasbumi Mataloko terletak disekitar perbatasan antara Kecamatan Golewa dan Kecamatan Aimere, Kabupaten Ngada, Flores, Nusa Tenggara Timur. Posisi geografi sumber panasbumi Mataloko terletak antara $08^{\circ} 48^{\prime} 30^{\prime \prime} \sim$ $08^{\circ} 53^{\prime} 30^{\prime \prime}$ Lintang Selatan dan $121^{\circ} 00^{\prime} \sim 121^{\circ} 05^{\prime}$ Bujur

\footnotetext{
*E-MAIL: oke_aji@plasa.com
}

Timur. Daerah panasbumi Mataloko mempunyai beberapa struktur sesar, antara lain [2] :

1. Sesar Bopa.

Terletak dibagian selatan daerah penyelidikan yaitu disekitar kampung Bopa. Arah sesar memanjang dari barat laut-tenggara, dimana blok sesar bagian utara hingga timur laut merupakan bok sesar yang bergerak relatif turun dibanding blok bagian selatan. Sesar ini dicirikan oleh adanya gawir sesar dan kelurusan morfologi di selatan kampung Bopa yang memisahkan endapan vulkanik Aimere dengan kelompok batuan hasil vulkanik muda dari kerucut-kerucut vulkanik yang terdapat di utara hingga timur laut.

2. Sesar Tudaluda.

Arah sesar memanjang dari barat daya - timur laut, dimana blok sesar bagian barat hingga barat laut merupakan bok sesar yang bergerak relatif turun. Tersebar

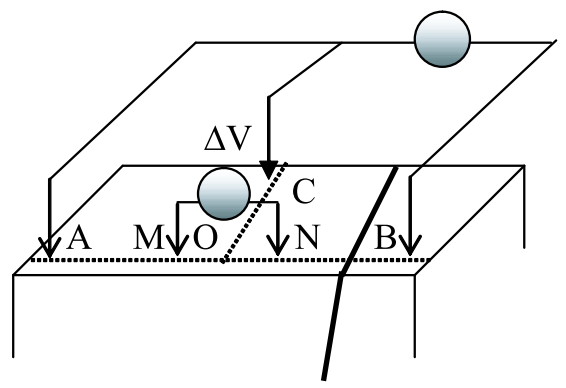

Gambar 1: Skema metode tahanan jenis konfigurasi Head-On. 

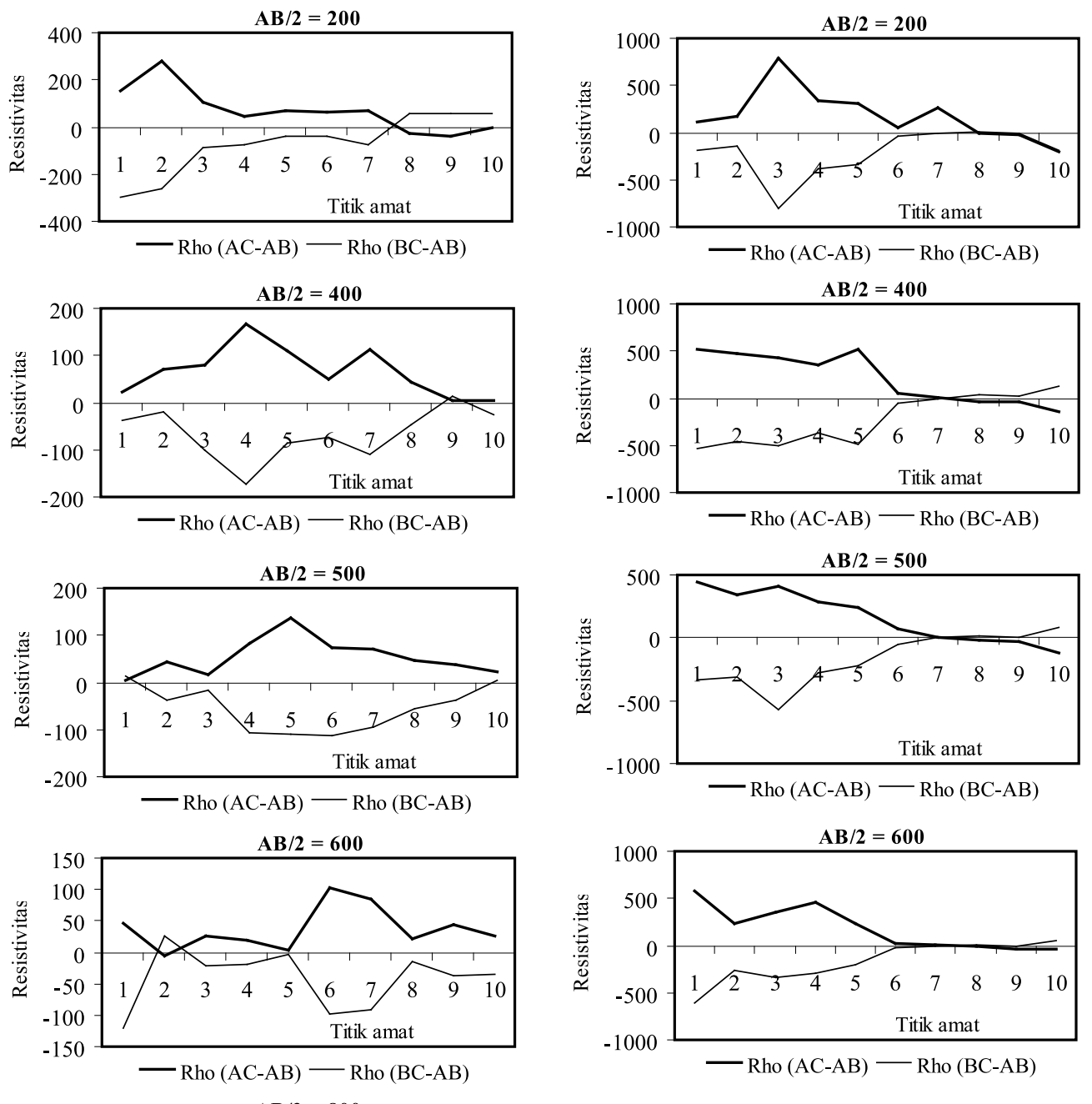

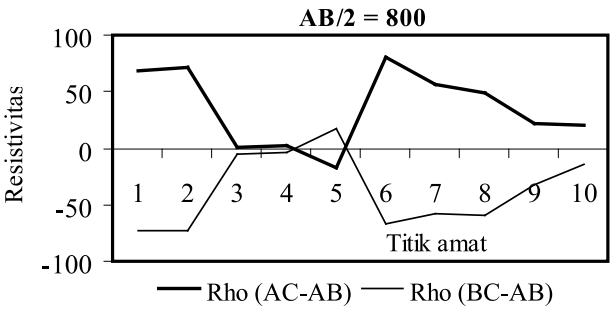

(b)

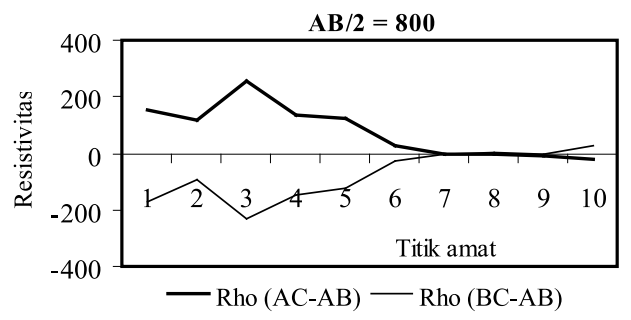

(a)

Gambar 2: Grafik resistivitas sebagai fungsi posisi titik pengamatan untuk masing-masing lintasan.

dibagian barat daya daerah penyelidikan, yaitu sepanjang sungai yang melalui kampung Tedaluda. Sesar ini dicirikan oleh kelurusan sungai yang melalui kampung Tedaluda, terbentuk pada sisi tubuh vulkanik tua kelompok Aimere.

3. Sesar Were.

Tersebar dibagian tenggara daerah penyelidikan, dise- latan kampung Were. Arah sesar adalah utara barat laut - selatan barat daya, dimana bagian barat daya merupakan blok sesar yang relatif bergerak turun. Dicirikan oleh adanya gawir sesar dan faset segitiga (trianguler facet) yang terdapat di selatan kampung Were. Batuan yang tersebarkan adalah endapan vulkanik Aimere. 


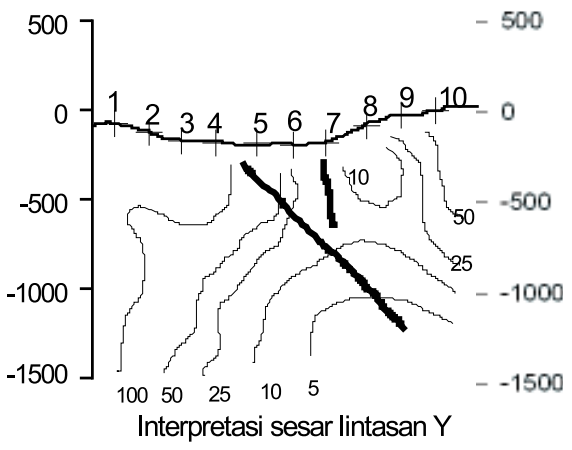

(a)

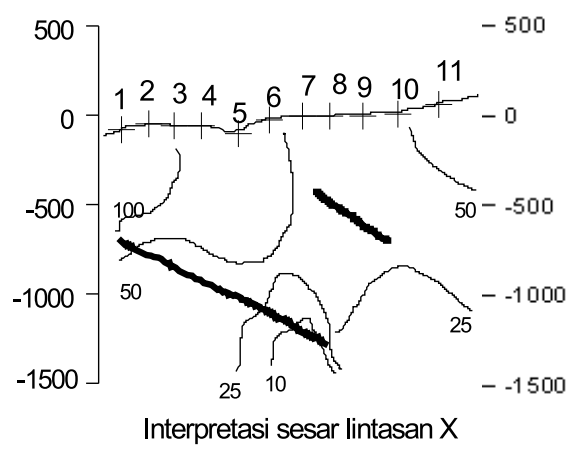

(b)

Gambar 3: Interpretasi sesar dari hasil pengukuran Head-On didaerah panas bumi Mataloko NTT.

Terletak dibagian selatan kampung Mataloko, sepanjang sungai Waeluja.. Arah sesar memanjang dari arah barat laut - tenggara. Blok sesar bagian utara hingga timur laut merupakan bok sesar yang bergerak relatif turun dibanding blok bagian selatan. Sesar ini dicirikan oleh adanya deretan mata air panas, kelurusan sungai Waeluja dan penyebaran batuan ubahan disekitar sesar. Kenampakan panasbumi di daerah Mataloko muncul melalui struktur sesar Waeluja ini.

\section{KONFIGURASI HEAD-ON (HALF-SCHLUMBERGER)}

Survey tahanan jenis pada umumnya bertujuan untuk mengetahui kondisi atau struktur geologi bawah permukaan berdasarkan variasi tahanan jenis batuannya [3]. Struktur geologi yang dapat dideteksi dengan metode ini terutama adalah yang mempunyai kontras tahanan jenis yang cukup jelas terhadap sekitarnya, misalnya untuk keperluan eksplorasi air tanah, mineral, geothermal (panasbumi). Prinsip pelaksanaan survey tahanan jenis adalah dengan menginjeksikan arus listrik melalui elektroda arus dan mengukur responnya (tegangan) pada elektroda potensial dalam suatu susunan (konfigurasi) tertentu [1]. Berdasarkan tujuan dan cara pengubahan jarak elektroda, survey geofisika dibagi menjadi dua cara : mapping dan sounding. Mapping dimaksudkan untuk mengetahui variasi horizontal atau lateral tahanan jenis batuan pada kedalaman tertentu. Jarak antar elektroda dibuat tetap sesuai dengan kedalaman daya penetrasi yang diinginkan, selanjutnya seluruh susunan elektroda dipindahkan menurut suatu lintasan tertentu. Sedangkan sounding dimaksudkan untuk mengetahui variasi tahanan jenis batuan terhadap kedalaman (secara vertikal). Jarak antar elektroda diperbesar dalam suatu arah bentangan pada suatu titik tertentu [6]. Konfigurasi Head-on (Half-Schlumberger) bertujuan untuk mengidentifikasi diskontinuitas lateral, terutama sesar (anomali konduktif lokal) sebagai pengontrol sirkulasi fluida. Konfigurasi elektroda seperti konfigurasi Schlumberger (AMNB) dengan menambahkan satu elektroda $\mathrm{C}$ yang terletak sedemikian rupahingga $\mathrm{OC} \perp \mathrm{AB}$ dan $\mathrm{OC} \ll \mathrm{AB}$. Arus diinjeksikan melalui elektroda AC atau BC, dan pengukuran beda potensial dilakukan pada elektroda MN [5]. Secara umum harga tahanan jenis semu dinyatakan oleh hubungan sebagai berikut :

$$
\rho_{a}=K \frac{\Delta V}{I}
$$

dimana, $K$ adalah faktor geometri, $\Delta V$ adalah beda potensial, dan $I$ adalah arus listrik.

Data yang diperoleh dari pengukuran di lapangan adalah besarnya arus dan beda potensial. Jarak $\mathrm{AB} / 2=200 \mathrm{~m}, 400 \mathrm{~m}$, $500 \mathrm{~m}, 600 \mathrm{~m}$, dan $800 \mathrm{~m}$, sedang jarak $\mathrm{MN} / 2=80 \mathrm{~m}$, serta jarak OC $=4000 \mathrm{~m}$. Terdapat dua buah lintasan $\mathrm{X}$ dan $\mathrm{Y}$ dengan masing-masing 11 dan 10 titik amat.

$$
\begin{aligned}
& \rho_{a}^{A B}=2 \pi\left(\frac{1}{A M}-\frac{1}{B M}-\frac{1}{A N}+\frac{1}{B M}\right)^{-1} \frac{\Delta V}{I} \\
& \rho_{a}^{A C}=2 \pi\left(\frac{1}{A M}-\frac{1}{C M}-\frac{1}{A N}+\frac{1}{C N}\right)^{-1} \frac{\Delta V}{I}
\end{aligned}
$$

Data dianggap memenuhi syarat jika hubungan berikut terpenuhi :

$$
\rho_{a}^{A B}=\frac{\rho_{a}^{A c}+\rho_{a}^{B C}}{2}
$$

\section{ANALISIS}

Dari hasil pengukuran tahanan jenis konfigurasi Head-On (Half-Schlumberger) daerah panasbumi Mataloko yang dilakukan pada 21 titik amat, masing-masing lintasan sebanyak 11 titik amat pada lintasan $\mathrm{X}$ dan 10 titik amat pada lintasan $\mathrm{Y}$, memberikan penafsiran zona sesar yang digambarkan sebagai titik-titik persilangan kedua kurva yang menunjukkan posisi sesar pada kedalaman yang sesuai dengan bentangan $\mathrm{AB} / 2$. Sesar dapat digambarkan pada penampang tahanan jenis dari kedua lintasan sebagai garis yang menghubungkan titik-titik posisi sesar pada kedalaman yang berbeda. Lintasan Y :

Pada penampang lintasan Y, diperkirakan sesar yang hampir tegak lurus pada titik amat TA 7. Sesar ini selanjutnya 
dipotong oleh sesar kedua sehingga memberikan kemungkinan berkembangnya aktivitas panasbumi mulai dari TA $6-9$. Kemungkinan sesar ini apabila diproyeksikan ke permukaan akan membentuk sudut sekitar $53^{\circ}$, yang diperkirakan sebagai sesar Waeluja. Arah sesar adalah baratl laut - tenggara, jenis sesar merupakan sesar normal, dimana blok sesar bagian utara merupakan blok sesar yang relatif bergerak turun dibanding blok sesar bagian selatan. Diperkirakan struktur sesar Waeluja ini sebagai struktur pengontrol sirkulasi fluida daerah panasbumi Mataloko. Dilapangan sesar Waeluja ini ditandai dengan adanya pemunculan fumarol dan deretan mata air panas, kelurusan sungai Waeluja dan penyebaran batuan ubahan disekitar sesar. Lintasa X :

Pada penampang lintasan $\mathrm{X}$, kemungkinan terdapat dua buah sesar. Sesar pertama yang kemiringannya hampir sama dengan sesar yang terdapat pada lintasan $\mathrm{Y}$ dan hanya terbentuk mulai $\mathrm{AB} / 2=200 \mathrm{~m}$ hingga $\mathrm{AB} / 2=400 \mathrm{~m}$. Sesar ini diperkirakan berhubungan dengan sesar Waeluja. Kemungkinan sesar lainnya terdapat pada penampang lintasan $\mathrm{X}$ adalah pada TA 1, TA 2, TA 3 dan TA 5.

\section{SIMPULAN}

Metode Head-on (Half-Schlumberger) dapat digunakan untuk mengidentifikasi diskontinuitas lateral, terutama struktur sesar (anomali konduktif lokal) bawah permukaan sebagai pengontrol sirkulasi fluida. Secara umum hasil pengukuran menunjukkan adanya beberapa sesar, salah satunya diperkirakan sebagai sesar Waeluja. Kemiringan sesar tersebut seki$\operatorname{tar} 53^{\circ}$ sebagai sesar normal, dan mengarah barat laut - tenggara. Diperkirakan sistem pengontrol sirkulasi fluida untuk daerah panasbumi Mataloko adalah sesar Waeluja tersebut.
[1] M. P. Hochstein,Introduction to Geothermal Prospecting, Geothermal Institut, University of Auckland, 1982.

[2] Fredy Nanlohi, dkk., Geologi Daerah Panasbumi Mataloko, Kabupaten Ngada - Flores Nusa Tenggara Timur, Laporan Direktorat Vulkanologi, 1997.

[3] H. Grandis, Penerapan Metode Gaya Berat dan Tahanan Jenis Dalam Eksplorasi Pendahuluan Daerah Prospek Panasbumi, Tugas Akhir Jurusan GM - ITB, 1986.
[4] D. S. Parasnis, Principles of Applied Geophysics, second Edition, Chapman and Hall, New York, 1972.

[5] W. M. Telford, L. P. Geldart, and R. E. Sheriff, Applied Geophysics, Second Edition, Cambridge and Hall, New York, 1990.

[6] O. Koefoed, Geosounding Principles : Resistivity Sounding Measurement, Elsevier, 1979. 